\title{
Differential effects of strength versus power training on bone mineral density in postmenopausal women: a 2-year longitudinal study
}

\author{
Simon von Stengel, Wolfgang Kemmler, Dirk Lauber, Willi A Kalender, Klaus Engelke
}

Br J Sports Med 2007;41:649-655. doi: 10.1136/bjsm.2006.033480

See end of article for authors' affiliations

\section{Correspondence to}

Dr S von Stengel, Institute of Medical Physics, University

of Erlangen, Henkestr 91,

91052 Erlangen, Germany; simon.von.stengel@imp.unierlangen.de

Accepted 6 March 2007 Published Online First 5 June 2007
Objectives: To investigate the effect of two different schemes of loading in resistance training on bone mineral density (BMD) and pain in pretrained postmenopausal women.

Methods: 53 pretrained women (mean (SD) age 58.2 (3.7) years) who carried out a mixed resistance and gymnastics programme were randomly assigned to a strength training (ST) or power training (PT) group. The difference between the two groups was the movement velocity during the resistance training (ST, $4 \mathrm{~s}$ (concentric)/4 s (eccentric); PT, explosive/4 s). Otherwise both groups carried out periodised progressive resistance training (10-12 exercises, 2-4 sets, 4-12 repetitions at 70-92.5\% of the one-repetition maximum (2/week) for 2 years. Mechanical loading was determined with a force measuring plate during the leg press exercise. At baseline and after 2 years, BMD was measured at different sites with dual $x$-ray absorptiometry. Pain was assessed by questionnaire.

Results: Loading magnitude, loading/unloading rate, loading amplitude and loading frequency differed significantly $(p<0.001)$ between the two groups. After 2 years, significant between-group differences were detected for BMD (PT, $-0.3 \%$; ST, $-2.4 \% ; \mathrm{p}<0.05$ ) and bone area (PT, $0.4 \% ; \mathrm{ST},-0.9 \% ; \mathrm{p}<0.05$ ) at the lumbar spine. At the hip, there was a non-significant trend in favour of the PT group. Also the incidence of pain indicators at the lumbar spine was more favourable in the PT group.

Conclusion: The results show that PT may be superior for maintaining BMD in postmenopausal women. Furthermore, PT was safe as it did not lead to increased injury or pain.
L ow bone mineral density (BMD) is a major risk factor for osteoporotic fracture. Therefore prevention of age-related bone loss is important, in particular, during the critical phase of the menopause. Recent meta-analyses of exercise studies have confirmed the positive effect of physical exercise on BMD in postmenopausal women. ${ }^{1-4}$ It is doubtful, however, whether the most effective strategy to maintain or regain BMD has yet been found.

Results from cross-sectional studies with athletes of different sports disciplines show that high-impact load-bearing activities such as sports competitions and gymnastics ${ }^{5-8}$ and activities associated with high muscular tension such as weightlifting ${ }^{7-11}$ are related to high BMD. For optimisation of exercise regimens, two main components have to be considered: the differential impact of the various mechanical stimuli on bone, and the differential generation of these stimuli by specific physical activities or exercises.

Strength is the capacity of muscle to generate force, and power is defined as the product of force and velocity. Thus power training (PT) is characterised by a high velocity of muscle shortening. The focus of this study is quantification of the mechanical loading characteristics of strength training (ST) versus PT, and investigation of the effect of these two training types on BMD in postmenopausal women. We hypothesise that a high movement velocity (PT) results in more pronounced stimulation than a low movement velocity (ST) by producing higher strain rates. On the basis of this hypothesis, we further assume that PT is more effective in maintaining BMD in postmenopausal women. As PT is characterised by explosive muscle contractions which produce higher stress on tendons and joints, it may have a higher risk of discomfort, pain and injury. Thus, we also determined the exercise-related incidence of pain by analysing pain intensity and frequency at different skeletal sites. We here report the 2-year results of a study in pretrained postmenopausal women. The first-year results have been published elsewhere. ${ }^{12}$

\section{METHODS}

This study was approved by the ethics committee of the University of Erlangen (Ethik Antrag S21-22112-81-00) and the German and Bavarian radiation safety agencies (Bundesamt für Strahlenschutz: Z2.1.2-22462/2-2002-016).

\section{Subjects}

Fifty three osteopenic postmenopausal woman (mean (SD) age 58.2 (3.7) years; 4-11 years post menopause) who had participated in the training arm of the EFOPS study for 3 years ${ }^{13}$ were group-wise randomly assigned to an ST $(n=28)$ or PT $(n=25)$ programme. Before the beginning of the study, none of the subjects had any diseases or took any medication that affected bone metabolism.

\section{Intervention programme}

Both groups carried out two supervised sessions of resistance training (60 min/week), one supervised session of gymnastics (60 min/week) and one non-supervised home training session (20 min/week). On the basis of calcium and vitamin $\mathrm{D}$ results from an individual nutritional analysis, participants received supplemental calcium and vitamin $\mathrm{D}$ to ensure a total daily intake of $1500 \mathrm{mg}$ and $500 \mathrm{IE}$, respectively.

Abbreviations: IRM, one-repetition maximum; BMD, bone mineral density; PT, power training; ST, strength training 

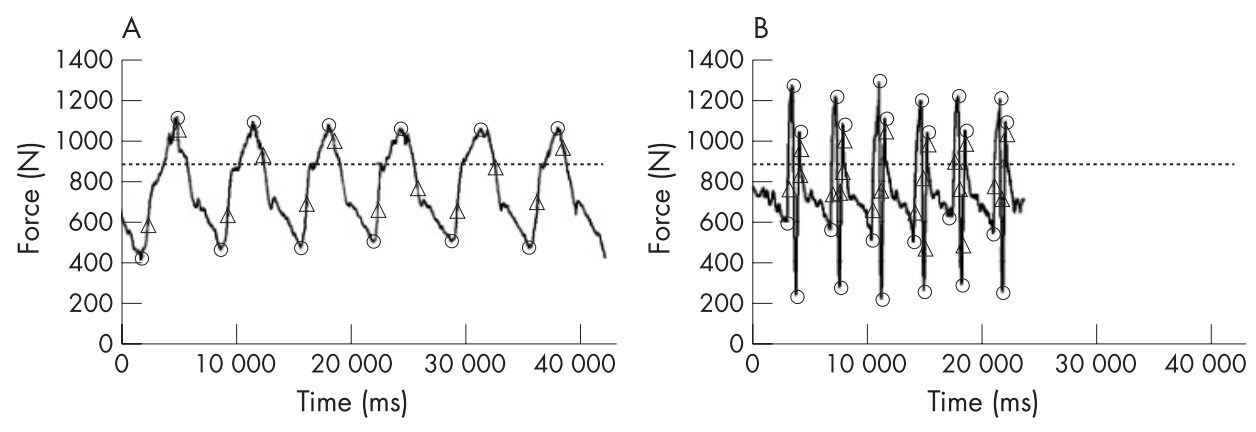

Figure 1 Characteristic force-time curves for strength training $(A)$ and power training (B). The maxima and minima of each repetition are marked by small circles. Maximal loading and unloading rates are marked for each repetition by small triangles. The dashed line indicates the force due to body weight.

\section{Weightlifting session}

Each resistance training session consisted of three sequences: 20 min warm-up programme (low/high-impact aerobic at 70$85 \%$ of maximum heart rate), short jumping sequence $(4 \times 15$ multidirectional jumps), resistance sequence (40 min). ${ }^{14}$ In the high-intensity, periodised weightlifting programme, all main muscle groups were trained on machines (Technogym, Gambettola, Italy). The following dynamic exercises were used: horizontal leg press, leg curls, bench press, rowing, leg adduction and abduction, abdominal flexion, back extension, lat pulley, hyperextension, leg extension, shoulder raises and hip flexion. A progressive, periodised design was used, which was characterised by 12 -week periods of high-intensity training (70-92.5\% of the one-repetition maximum (1RM)) interspersed with 4-5 weeks of lower training intensity (50\% of IRM) ensuring enough time for adaptation and regeneration.

The only difference between the ST and PT study arms was the velocity with which the exercises were carried out. In the ST mode, movements were performed in a $4 \mathrm{~s}$ (concentric)/4 s (eccentric) scheme. The subjects in the PT group were instructed to perform the concentric part "as fast as possible", whereas the eccentric period was to be carried out slowly (4s). In the home training and gymnastics sessions described next, there were no differences between ST and PT.

\section{Gymnastic session}

The purpose of the weekly gymnastic programme was to improve fall-related abilities, in particular balance and coordination, strength, endurance and flexibility. The session started with aerobics or games, followed by balance exercises. Further isometric and dynamic strength exercises for the trunk, shoulders and arms were performed, partly using elastic bands. At the end of the session, stretching exercises were carried out.

\section{Home training session}

All participants were requested to carry out a 20 min home training session once a week. In this session, subjects received written instructions to perform selected strength and stretching exercises also carried out in the gymnastic session.

\section{Measurements}

Characterisation of differential mechanical loading

At 6 months into the study, when the subjects had become accustomed to the new training modality, reaction forces were evaluated in 16 members of the PT group and 18 members of the ST group with a force plate (mtd-Systems, Neuburg v Wald, Germany) during the leg press procedure. Force-time curves were recorded over six repetitions carried out with loads corresponding to $\sim 75 \%$ of 1 RM. From these curves, loading magnitude, amplitude, frequency and maximum loading and unloading rates were extracted and compared between PT and ST groups.
The loading magnitude was defined as the mean of the six force maxima normalised by the lifted weight (fig 1). Analogously the loading amplitude was calculated as the mean of the differences between the six maxima and minima normalised by lifted weight (fig 1). The maximum loading and unloading rates $(\mathrm{N} / \mathrm{ms})$ were determined from the derivatives and calculated as mean rates of the six maxima or the six minima, respectively. Spectral loading characteristics were assessed by decomposing the force-time curves into sinusoidal components using fast Fourier transforms. The decomposition gave the dependence of force on frequency, the so-called frequency spectrum of the force. For the statistical analysis, the frequency spectrum between 0 and $3 \mathrm{~Hz}$, which is the range of relevant amplitudes, was divided into six intervals of $0.5 \mathrm{~Hz}$ each. Finally, a Fourier synthesis was performed to analyse the contribution of each $0.5 \mathrm{~Hz}$ interval to the original signal.

\section{Bone densitometry}

BMD at the lumbar spine (L1-L4), the proximal femur (total hip and sub regions) and the forearm (distal forearm and ultradistal radius) were measured at baseline and after 1 year and 2 years by dual $x$-ray absorptiometry (QDR 4500A; Hologic, Bedford, MA, USA) using standard protocols.

\section{Pain}

Pain frequency and intensity at various skeletal sites (spine segments, big joints, small joints) were assessed at baseline and after 1 year and 2 years by a questionnaire described by Jensen et $a l^{15}$ and the Osteoporosis Quality of Life Study Group. ${ }^{16}$

\section{Anthropometric data}

Weight and body composition was assessed using impedance scales (Tanita BF 305; Tanita, Tokyo, Japan).

\section{Maximum strength}

Maximum isometric strength of the trunk extensors and flexors was determined using a Schnell M-3 dynamometer (Schnell, Peutenhausen, Germany). Maximal dynamic muscle strength of the legs (leg press) and the chest (seated bench press) was determined at the training machines using IRM tests.

\section{Nutritional data}

Individual dietary intakes were assessed from a 5-day diary analysed using Prodi-4,5/03 Expert software (Wissenschaftlicher Verlag, Freiburg, Germany).

\section{Statistical analysis}

The Kolgomorov-Smirnov test was used to check for normal distribution. Homogeneity of variance was determined using the Levine F-test. Student $t$ tests were used to compare the baseline characteristics of the two groups. Changes between baseline and follow-up within the groups were analysed by 
Table 1 Anthropometric and nutritional data at baseline for subjects in the strength training (ST) and power training (PT) groups

\begin{tabular}{lll}
\hline Variable & ST $(\mathbf{n}=\mathbf{2 4})$ & PT $(\mathbf{n}=\mathbf{2 2})$ \\
\hline Age (years) & $59.04(3.76)$ & $57.35(3.63)$ \\
Time after menopause (years) & $4.50(2.29)$ & $4.48 .1(2.37)$ \\
Height $(\mathrm{cm})$ & $165.4(6.8)$ & $163.8(6.6)$ \\
Weight $(\mathrm{kg})$ & $65.8(10.4)$ & $69.9(8.7)$ \\
Body fat $(\%)$ & $34.9(6.7)$ & $36.3(5.8)$ \\
Energy intake $(\mathrm{kJ} /$ day) & $8918(2388)$ & $8757(1122)$ \\
Protein intake $(\mathrm{g} /$ day) & $74.0(19.3)$ & $12.0(13.6)$ \\
Calcium intake $(\mathrm{mg} /$ day) & $1285(369)$ & $1488(270)$ \\
Phosphorus intake $(\mathrm{mg} /$ day) & $1491(403)$ & $4.09(3.79)$ \\
Vitamin D intake $(\mu \mathrm{g} /$ day) & \\
\hline Values are mean $(\mathrm{SD})$. & $3.26(3.09)$ & \\
*Data from 5-day dietary records. & &
\end{tabular}

paired $t$ tests. Within-group changes were calculated as percentage changes; unpaired t tests were used to compare these differences in the two groups. For variables that were not normally distributed, Wilcoxon or Whitney-Mann U tests were applied instead of t tests. Because of the multiple test problem, we also performed a two-way analysis of variance with repeated measures. The type of resistance training (PT versus ST) was used as between-group factor, and the time between baseline and follow-up visit was used as within-group factor. The results of the two statistical methods were identical. All tests were two-tailed, and a 5\% probability level was considered significant. We used SPSS V.12.0 (SPSS Inc, Chicago, Illinois, USA) for statistical analysis. The fast Fourier transformation and spectral analysis of the force-time curves were carried out in Excel 2003 (Microsoft Corp).

\section{RESULTS}

At baseline, 53 women were included in the study. Five subjects dropped out during the 2 years of intervention for personal reasons. Another two subjects were excluded from the data analysis because they had developed a disease that affected bone metabolism. Thus 24 women from the ST group and 22 women from the PT group were included in the analysis.

The attendance rate was similar in the two groups: $2.2(0.4)$ sessions per week in the ST group and $2.3(0.5)$ sessions in the PT group. Table 1 shows anthropometric and nutritional baseline data for both groups, and table 2 compares osteodensitometric and muscle-strength variables at baseline. Except for leg press values $(\mathrm{p}<0.05)$, no significant group differences were detected.

\section{Mechanical loading of power and strength training}

Figure 1 shows two characteristic force-time curves, one for a subject in the ST group (A) and one in the PT group (B). As a consequence of the explosive muscle contraction, the curves are quite different, with higher maxima and minima and higher frequencies in the PT group. Compared with the ST group, the PT group showed a $16 \%$ higher relative loading magnitude, a $82 \%$ higher relative loading amplitude, and $262 \%(612 \%)$ higher loading (unloading) rate. All differences were highly significant $(\mathrm{p}<0.001)$.

Figure 2 shows the results of the frequency analysis. It can be seen that in the ST group the $0-0.5$ frequency range accounts for most of the original signal (74\%), whereas in the PT group there are high amplitudes from 0 to $2.5 \mathrm{~Hz}$. In the PT group, frequencies greater than $\mathrm{l} \mathrm{Hz}$ account for $77 \%$ of the signal compared with $14 \%$ in the ST group. The differences between the groups were highly significant for all variables $(\mathrm{p}<0.001)$.

\section{Osteodensitometry}

Figure 3 illustrates the results of the osteodensitometric measurements as percentage changes between baseline and year 2 for BMD and area. Figure 3A shows the results for the lumbar spine (L1-L4). Whereas the ST group lost BMD and area significantly, there were no differences in the PT group. Between-group differences were significant for both variables. Figure $3 \mathrm{~B}$ shows the corresponding results for the total hip, femoral neck and trochanter. The ST group significantly lost BMD at the total hip and femoral neck. However, betweengroup differences were not significant. At the forearm (fig 3C) no changes were observed at all.

\section{Pain and injuries}

Figure 4 gives results for pain frequency and intensity in the lower back and big joints (hip, knee, shoulder). These regions in particular were loaded during our resistance training regimen. In the ST group, a significant increase in pain intensity at the lumbar spine was observed, whereas a slight

Table 2 Osteodensitometric and maximum muscle-strength variables at baseline for subjects in the strength training (ST) and power training (PT) groups

\begin{tabular}{lll}
\hline Variable & ST $(\mathbf{n}=\mathbf{2 2})$ & PT (24) \\
\hline DXA lumbar spine $\left(\mathrm{g} / \mathrm{cm}^{2}\right)$ & $0.869(0.075)$ & $0.864(0.078)$ \\
DXA total hip $\left(\mathrm{g} / \mathrm{cm}^{2}\right)$ & $0.862(0.090)$ & $0.848(0.056)$ \\
DXA ultradistal radius $\left(\mathrm{g} / \mathrm{cm}^{2}\right)$ & $0.399(0.052)$ & $0.411(0.047)$ \\
Maximum isometric trunk flexion (N.m) & $73.04(15.80)$ & $75.27(14.69)$ \\
Maximum isometric trunk extension (N.m) & $137.9(24.3)$ & $136.4(29.0)$ \\
Maximum dynamic leg press (kg) & $176.9(30.4)$ & $201.5(37.5)^{*}$ \\
Maximum dynamic bench press (kg) & $46.13(7.31)$ & $48.95(8.81)$ \\
\hline
\end{tabular}

DXA, dual $x$-ray absorptiometry.

Values are mean (SD).

*Significant between-group difference $(p<0.05)$. 


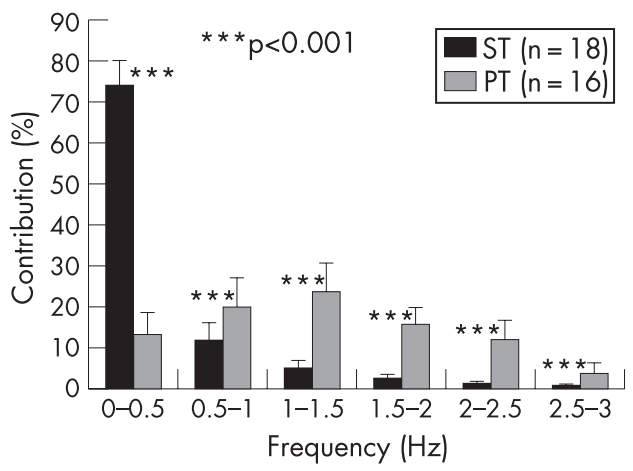

Figure 2 Contribution of the six $0.5 \mathrm{~Hz}$ frequency intervals to the total signal in the strength training (ST) and power training (PT) group. Values are mean (SD). Significant between-group differences are marked with asterisks.

non-significant decrease was found in the PT group. This resulted in a significant between-group difference for pain intensity in the lumbar spine. At the spine, similar but insignificant results were found for pain frequency. For the big joints, a significant decrease in pain frequency was even observed in the PT group. No significant within-group or between-group differences could be detected for pain in the small joints or the thoracic or cervical spine.

\section{DISCUSSION}

In our 2-year exercise study in postmenopausal woman, we determined the differential effects of PT versus ST. The first aim was of a technical nature: to show that a difference in training velocities translated into differential effects of the mechanical loading stimuli. The main hypothesis was based on the assumption that different mechanical stimuli result in differences in BMD in our groups of postmenopausal women.

We found a significant impact of the training scheme on the loading stimuli varying from $16 \%$ to $611 \%$ between the PT and ST group. The effect on loading magnitude was lowest; the effect on loading and unloading rate was highest. However, these results do not answer the question whether loading parameters determined by measuring external reaction forces can be used to estimate internal loading and strain of bones. There is not much literature on this topic. Bassey et al ${ }^{17}$ simultaneously determined ground reaction and internal forces at the proximal femur via an instrumented hip implant during different activities (walking, jumping, jogging). They found that the ground reaction forces were significantly related to the internal peak force and the internal force rate. As the bone strain is directly proportional to the applied force, ${ }^{18}$ we conclude that the external reaction forces can be used to estimate the internal forces and the resulting bone strains of loaded bones.

There are very few human studies that have quantified the effect of specific mechanical stimuli on bone. The studies that do exist almost exclusively focus on loading magnitude and investigate the effect of low versus high intensity resistance training. ${ }^{19-24}$ One study showed that high-impact (jumping) exercises were significantly more efficient in positively affecting BMD than low-impact exercises but did not quantify the loading rate. ${ }^{19}$ To our knowledge, the present study is the first longitudinal human study that quantifies the mechanical loading of different training strategies in combination with analysis of the BMD.

In contrast with human studies, numerous published animal studies have investigated the influence of mechanical stimuli on bone. Their results are very useful in the discussion of the outcome of our study. The isolated effect of strain magnitude
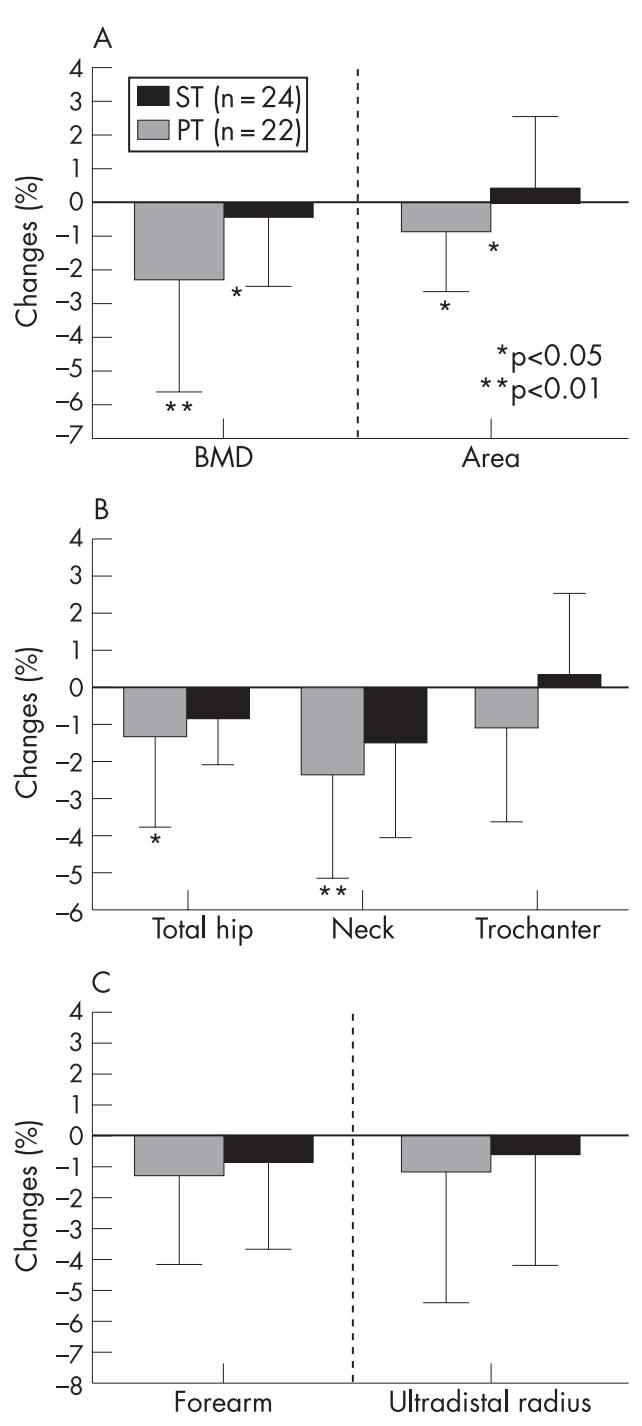

Figure 3 Percentage changes in bone mineral density (BMD), measured by dual $x$-ray absorptiometry, between baseline and year 2 at $(A)$ the lumbar spine (LI-L4), (B) the proximal femur and (C) the forearm in the strength training (ST) and power training (PT) group. Values are mean (SD). Significant between-group differences are marked with asterisks.

was analysed in two studies using the isolated avian ulna model. ${ }^{25}{ }^{26}$ In accordance with the mechanostat theory, ${ }^{27}$ at a threshold of about $1000 \mu \epsilon$, bone formation was enhanced and the newly formed bone increased approximately linearly with strain magnitude.

The isolated influence of the strain rate is addressed in several publications. All show that a higher strain rate is associated with a higher adaptive bone response. ${ }^{28-30}$ Two studies compared the mechanical loading characteristics of walking, running (low-impact exercises) and drop jumps (high-impact exercises) at the tarsometatarsus of roosters. ${ }^{31} 32$ Compared with walking and running, drop jumps produce only moderately higher strain magnitudes $(+30 \%$ and $+11 \%$, respectively) but much higher strain rates $(+740 \%$ and $+256 \%$, respectively). In contrast with treadmill running, drop jumps increased bone formation significantly. These results emphasise the importance of strain rate. Another study using the rat ulna loading model shows that loading and unloading rates are of equal importance for stimulating bone formation. ${ }^{33}$

The isolated assessment of mechanical stimuli is not easy, and studies must be interpreted carefully. For example, in the 


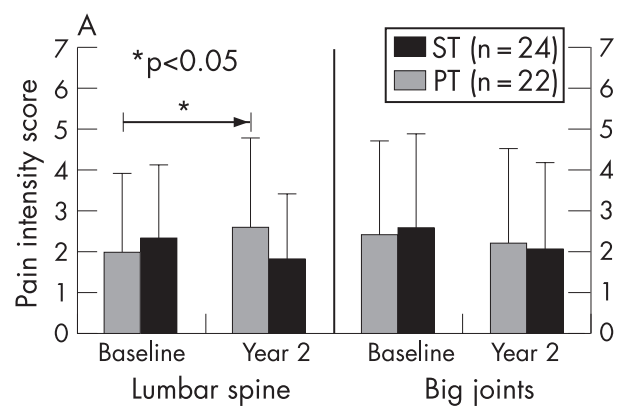

Lumbar spine

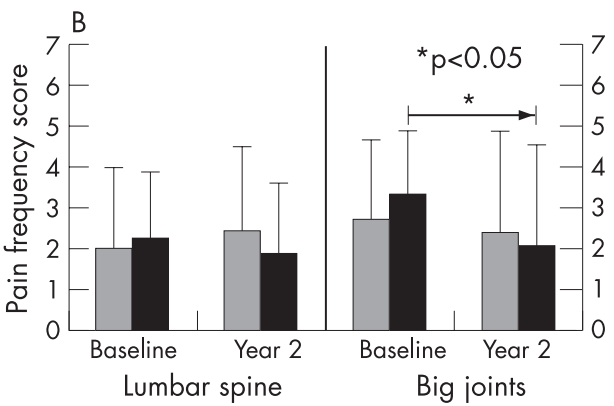

Figure 4 Pain frequency $(\mathrm{A})$ and pain intensity (B) at baseline and year 2 at the lumbar spine and big joints in the strength training (ST) and power training (PT) group. Values are mean (SD). Significant withingroup changes are marked with an asterisk. study of Turner et $a^{30}$ mentioned above, the loading rate was increased by raising the loading amplitude $(0,18,36,54 \mathrm{~N})$ of a sinusoidal loading at constant loading magnitude (54 N). In other words, there was not complete unloading. The enhanced bone formation may be attributed to a combination of higher strain rates and higher strain amplitudes. There is some speculation that there may be an important role for strain amplitude in increasing fluid flow, which some researchers suggest is a key stimulus of mechanotransduction. ${ }^{34}$

The fourth stimulus investigated in our study was loading frequency. Most animal studies have shown an increase in bone formation rate with increasing frequency. ${ }^{35-37}$ However, most used much higher frequencies $(10-50 \mathrm{~Hz})$ than those that result from exercise, which are predominantly in a range up to 3-4 Hz (fig 2). Thus the results of these animal studies are more relevant for the construction of vibration platforms. ${ }^{38-41}$ However, one animal study used loading frequencies between 0.2 and $2.0 \mathrm{~Hz}^{37}$ It showed that higher frequencies were associated with higher osteogenic response.

In summary, all these studies indicate that PT should be more effective than ST in stimulating the mechanosensitive bone cells and in inducing bone adaptation, be it through the pathways of higher loading magnitude or amplitude, higher loading and unloading rate, higher frequency, or a combination of these factors. Overall, our study results confirm this

\section{What is already known on this topic}

- Physical activity and sport positively influence bone mineral density (BMD).

- High-impact load-bearing exercises and high-intensity strength training are more effective than endurance and low-impact/intensity training.

- Bone is sensitive to several mechanical loading variables such as loading magnitude, rate and frequency. However, in vivo, their differential effects on bone are not fully understood.

\section{What this study adds}

- This study investigates the effect of the movement velocity during weightlifting training on mechanical loading variables and compares the effects of strength and power training on BMD.

- Higher movement velocity, in particular, results in higher loading rates and is more effective at the lumbar spine but not at the hip. conclusion. After 2 years, there was a significant BMD loss at the spine in the ST group versus no loss in the PT group, and in the proximal femur there was a trend of a greater BMD loss in the ST group compared with the PT group. Between-group differences reached significance at the lumbar spine.

Unfortunately, we did not use more sophisticated techniques to investigate BMD or bone structure changes such as quantitative CT or high-resolution MRI. Thus, for example, differential effects on cortical and trabecular bone could not be investigated. Interestingly, the 2-year results were slightly different from the 1 -year data ${ }^{12}$ in significant between-group differences at the lumbar spine and total hip. After 1 year, total hip BMD in the PT group was constant (0.0 (1.7)\%, NS); after 2 years, we found a small decrease of $-0.8(1.3) \%$ that was still not significant. In contrast, the decrease in the ST group was similar in both years (year $1,-1.2(1.5) \%, \mathrm{p}<0.01$; year $2,-1.3$ $(2.5) \%)$. A cautious, although not statistically proven, interpretation of our results might conclude that the superior effect of the PT in the first year was eroded in the second year. This is suggested by the fact that, in the spine area in the PT group, a slight BMD increase $(+0.7(2.1) \%$, NS) after year 1 turned into a small decrease $(-0.4(2.2) \%)$ in the second year. Again the use of more advanced techniques such as quantitative CT may be preferable to dual $x$-ray absorptiometry to clarify this questions.

This may indicate habituation effects, also observed by other authors, ${ }^{22}{ }^{42-44}$ and support the model of Schriefer et $a l^{45}$, according to which bone adapts mainly to changes in its mechanical environment based on the principle of cellular accommodation. All women that participated in our study had previously exercised in the EFOPS programme. Compared with ST, PT was an unaccustomed stimulus and therefore initially was more effective at maintaining BMD. In the second year, the women had become accustomed to the new training stimulus and PT lost its superiority. However, as this possible interpretation of our results is not backed by hard statistical evidence, we will not discuss it further.

There are very few intervention studies using PT in older people, ${ }^{46-55}$ and this may be one reason why the overall benefits of PT in this age group are controversial. Obviously, PT results in greater stress on muscles, tendons and joints and may thus imply a higher risk of injuries. Thus older people are generally advised to perform weightlifting exercises with low movement velocity. ${ }^{56}$

In our study, there was no increased incidence of injury or pain associated with the high movement velocity. We attribute this to the fact that our subjects were pretrained and well adapted to high-intensity resistance at the study start. In the preceding EFOPS training, the subjects performed a progressive weightlifting programme over a period of 3 years. We further attribute these results to the periodised design, characterised by 12-week periods of high-intensity training (70-92.5\% of 1RM) interspersed by $4-5$ weeks of lower training intensity (50\% of IRM) ensuring enough time for adaptation and regeneration. 
However, we admit that, to date, little is known about the long-term effects of PT in older subjects, and consequently it is too early to generalise PT recommendations for this group.

In summary, this study shows that, at least at the spine, PT was superior to ST with respect to increasing BMD, and therefore may have greater potential for preventing osteoporosis. It can be assumed that, for healthy older people who can tolerate high-intensity training, a resistance programme with PT may not only benefit bone but also be beneficial in improving physical function and enhancing everyday functional abilities. ${ }^{49}{ }^{51}{ }^{57-60}$ Our results suggest that there should be no increase in pain and injury if sufficient slow adaptation to this strenuous training is allowed.

\section{ACKNOWLEDGEMENTS}

This work was supported by the state of Bavaria (Gesetz zur Förderung des wissenschaftlichen und künstlerischen Nachwuchses vom 18.12.1984). We further gratefully acknowledge support from Sanofi Synthelabo (Paris, France), who supplied calcium and vitamin D supplements, and mtd-Systems (Neuburg v. Wald, Germany), who supplied the force plates. We thank Manfred von Stengel for helpful discussions on the analysis of the force-time curves.

\section{Authors' affiliations}

Simon von Stengel, Wolfgang Kemmler, Willi A Kalender, Klaus Engelke, Institute of Medical Physics, University of Erlangen, Erlangen, Germany Dirk Lauber, Institute of Sports Science, University of Erlangen, Erlangen, Germany

Competing interests: None.

\section{REFERENCES}

1 Kelley GA. Exercise and regional bone mineral density in postmenopausal women: a meta-analytic review of randomized trials. Am J Phys Med Rehabil 1998;77:76-87.

2 Kemmler W, Engelke, K. A critical review of exercise training on bone mineral density in postmenopausal women. International Sports Medicine Journal 2004;5:67-77.

3 Wallace BA, Cumming RG. Systematic review of randomized trials of the effect of exercise on bone mass in pre- and postmenopausal women. Calcif Tissue Int 2000;67:10-18.

4 Wolff I, van Croonenborg JJ, Kemper HC, et al. The effect of exercise training programs on bone mass: a meta-analysis of published controlled trials in preand postmenopausal women. Osteoporos Int 1999;9:1-12.

5 Fehling PC, Alekel L, Clasey J, et al. A comparison of bone mineral densities among female athletes in impact loading and active loading sports. Bone 1995; 17:205-10.

6 Lee EJ, Long KA, Risser WL, et al. Variations in bone status of contralateral and regional sites in young athletic women. Med Sci Sports Exerc 1995;27:1354-61.

7 Morel J, Combe B, Francisco J, et al. Bone mineral density of 704 amateur sportsmen involved in different physical activities. Osteoporos Int 2001;12:152-7.

8 Risser WL, Lee EJ, LeBlanc A, et al. Bone density in eumenorrheic female college athletes. Med Sci Sports Exerc 1990;22:570-4.

9 Heinonen A, Oja P, Kannus $P$, et al. Bone mineral density of female athletes in different sports. Bone Miner 1993;23:1-14.

10 Heinrich CH, Going SB, Pamenter RW, et al. Bone mineral content of cyclically menstruating female resistance and endurance trained athletes. Med Sci Sports Exerc 1990;22:558-63.

11 Nilsson BE, Westlin NE. Bone density in athletes. Clin Orthop 1971;77:179-82.

12 von Stengel S, Kemmler W, Engelke K, et al. Power training is more effective for maintaining bone mineral density in postenopausal women. J Appl Physiol 2005;99:181-8.

13 Engelke K, Kemmler W, Lauber D, et al. Exercise maintains bone density at spine and hip EFOPS: a 3-year longitudinal study in early post-menopausal women. Osteoporos Int 2006;17:133-42.

14 Kemmler W, Engelke K, Lauber D, et al. Exercise effects on fitness and BMD in early postmenopausal women: 1 year EFOPS results. Med Sci Sports Exerc 2002;34:2115-23.

15 Jensen MP, Karoly P, Braver S. The measurement of clinical intensity: a comparison of six methods. Pain 1986;27:117-26.

16 Investigators. Measuring quality of life in women with osteoporosis. The Osteoporosis Quality of Life Study Group. Osteoporos Int 1997;7:478-87

17 Bassey EJ, Littlewood JJ, Taylor SJ. Relations between compressive axial forces in an instrumented massive femoral implant, ground reaction forces, and integrated electromyog-raphs from vastus lateralis during various 'osteogenic' exercises. J Biomech 1997;30:213-23.

18 Jiang $Y$, Zhao J, Rosen C, et al. Perspectives on bone mechanical properties and adaptive response to mechanical challenge. J Clin Densitom 1999;2:423-33.
19 Bassey EJ, Ramsdale SJ. Increase in femoral bone density in young women following high-impact exercise. Osteoporos Int 1994;4:72-5.

20 Bemben DA, Fetters NL, Bemben MG, et al. Musculoskeletal responses to highand low-intensity resistance training in early postmenopausal women. Med Sci Sports Exerc 2000;32: 1949-57.

21 Kerr D, Morton A, Dick I, et al. Exercise effects on bone mass in postmenopausal women are site-specific and load-dependent. J Bone Miner Res 1996;11:218-25.

22 Kerr D, Ackland T, Maslen B, et al. Resistance training over 2 years increases bone mass in calcium-replete postmenopausal women. J Bone Miner Res $2001 ; 16: 175-81$.

23 Maddalozzo GF, Snow CM. High intensity resistance training: effects on bone in older men and women. Calcif Tissue Int 2000;66:399-404.

24 Vincent KR, Braith RW. Resistance exercise and bone turnover in elderly men and women. Med Sci Sports Exerc 2002;34:17-23.

25 Rubin CT, Lanyon LE. Regulation of bone mass by mechanical strain magnitude. Calcif Tissue Int 1985;37:411-17.

26 Turner CH, Forwood MR, Rho JY, et al. Mechanical loading thresholds for lamellar and woven bone formation. J Bone Miner Res 1994;9:87-97.

27 Frost HM. Bone mass and the mechanostat. A proposal. Anat Rec 1987;219:1-19.

28 Mosley JR, Lanyon LE. Strain rate as a controlling influence on adaptive modeling in response to dynamic loading of the una in growing male rats. Bone 1998;23:313-18.

$29 \mathrm{O}^{\prime}$ Connor JA, Lanyon LE, MacFie $\mathrm{H}$. The influence of strain rate on adaptive bone remodelling. J Biomech 1982;15:767-81.

30 Turner $\mathrm{CH}$, Owan I, Takano Y. Mechanotransduction in bone: role of strain rate. Am J Physiol Endocrinol Metab 1995;269:E438-42.

31 Judex S, Zernicke RF. High-impact exercise and growing bone: relation between high strain rates and enhanced bone formation. J Appl Physiol 2000;88:2183-91.

32 Judex S, Zernicke RF. Does the mechanical milieu associated with high-speed running lead to adaptive changes in diaphyseal growing bone? Bone 2000;26:153-9.

33 Skerry TM, Peet Nm. "Unloading" exercises increases bone formation in rats. J Bone Miner Res 1997; 12:1520.

34 Weinbaum S, Cowin SC, Zeng Y. A model for the excitation of osteocytes by mechanical loading-induced bone fluid shear stresses. J Biomech 1994;27:339-60.

35 Hsieh YF, Turner CH. Effects of loading frequency on mechanically induced bone formation. J Bone Miner Res 2001;16:918-24.

36 Rubin CT, McLeod KJ. Promotion of bony ingrowth by frequency specific, lowamplitude mechanical strain. Clin Orthop 1994;298:165-74.

37 Turner CH, Forwood MR, Otter MW. Mechanotransduction in bone: do bone cells act as sensors of fluid flow? FASEB J 1994;8:875-8.

38 LaMothe JM, Zernicke RF. Rest insertion combined with high-frequency loading enhances osteogenesis. J Appl Physiol 2004;96:1788-93.

39 Rubin C, Turner AS, Mallinckrodt C, et al. Mechanical strain, induced noninvasively in the high-frequency domain, is anabolic to cancellous bone, but not cortical bone. Bone 2002;30:445-52.

40 Rubin C, Xu G, Judex S. The anabolic activity of bone tissue, suppressed by disuse, is normalized by brief exposure to extremely low-magnitude mechanical stimuli. FASEB J 2001;15:2225-9.

41 Warden SJ, Turner $\mathrm{CH}$. Mechanotransduction in the cortical bone is most efficient at loading frequencies of 5-10 Hz. Bone 2004;34:261-70.

42 Heikkinen J, Kyllonen E, Kurttila-Matero E, et al. HRT and exercise: effects on bone density, muscle strength and lipid metabolism. A placebo controlled 2-year prospective trial on two estrogen-progestin regimens in healthy postmenopausal women. Maturitas 1997:26:139-49.

43 Iwamoto J, Takeda T, Ichimura S. Effects of exercise training and detraining on bone mineral density in postmenopausal women with osteoporosis. J Orthop Sci $2001 ; 6: 128-32$.

44 Prince RL, Devine A, Dick I, et al. The effect of calcium supplementation (milk powder or tablets) and exercise on bone density in postmenopausal women. $J$ Bone Miner Res 1995; 10:1068-75.

45 Schriefer JL, Warden SJ, Saxon LK, et al. Cellular accommodation and the response of bone to mechanical loading. J Biomech 2005;38:1838-45.

46 Bean JF, Herman S, Kiely DK, et al. Increased Velocity Exercise Specific to Task (InVEST) training: a pilot study exploring effects on leg power, balance, and mobility in community-dwelling older women. J Am Geriatr Soc 2004;52:799-804.

47 Earles DR, Judge JO, Gunnarsson OT. Velocity training induces power-specific adap-tations in highly functioning older adults. Arch Phys Med Rehabil $2001 ; 82: 872-8$.

48 Fielding RA, LeBrasseur NK, Cuoco A, et al. High-velocity resistance training increases skeletal muscle peak power in older women. J Am Geriatr Soc 2002;50:655-62.

49 Foldvari M, Clark M, Laviolette LC, et al. Association of muscle power with functional status in community-dwelling elderly women. J Gerontol A Biol Sci Med Sci 2000;55:M192-9.

50 Hakkinen K, Kraemer WJ, Newton RU, et al. Changes in electromyographic activity, muscle fibre and force production characteristics during heavy resistance/power strength training in middle-aged and older men and women. Acta Physiol Scand 2001;171:51-62.

51 Henwood TR, Taaffe DR. Improved physical performance in older adults undertaking a short-term programme of high-velocity resistance training. Gerontology 2005;51:108-15.

52 Miszko TA, Cress ME, Slade JM, et al. Effect of strength and power training on physical function in community-dwelling older adults. J Gerontol A Biol Sci Med Sci 2003;58:171-5. 
53 Orr R, de Vos NJ, Singh NA, et al. Power training improves balance in healthy older adults. J Gerontol A Biol Sci Med Sci 2006;61:78-85.

54 Sayers SP, Bean J, Cuoco A, et al. Changes in function and disability after resistance training: does velocity matter? A pilot study. Am J Phys Med Rehabil 2003;82:605-13.

55 de Vos NJ, Singh NA, Ross DA, et al. Optimal load for increasing muscle power during explosive resistance training in older adults. J Gerontol A Biol Sci Med Sci 2005;60:638-47.

56 Evans WJ. Exercise training guidelines for the elderly. Med Sci Sports Exerc 1999;31:12-17.

57 Bassey EJ, Fiatarone MA, O'Neill EF, et al. Leg extensor power and functional performance in very old men and women. Clin Sci (Lond) 1992:82:321-7.

58 Skelton DA, Greig CA, Davies JM, et al. Strength, power and related functional ability of healthy people aged 65-89 years. Age Ageing 1994;23:371-7.

59 Suzuki T, Bean JF, Fielding RA. Muscle power of the ankle flexors predicts functional performance in community-dwelling older women. J Am Geriatr Soc 2001;49:1161-7.

60 Rantanen T, Avela J. Leg extension power and walking speed in very old people living independently. J Gerontol A Biol Sci Med Sci 1997;52:M225-31.

\section{COMMENTARY}

A detailed description of an exercise programme is often required by our patients. This paper is one of the first to show the different effects of two training regimens performed with the same equipment. Osteoporosis and falling are the most common causes of fractures in older people, and exercise plays an important role in their prevention. To find the most efficient exercise regimen for each individual subject is required. Power training may be a good option for preserving bone mass in postmenopausal women.

Elisabeth Preisinger Institut für physikalische Medizin und Rehabilitation, Wien, Austria; elisabeth.preisinger@wienkav.at

\section{International Forum on Quality and Safety in Health Care}

23-25 April 2008

Le Palais des Congrès de Paris

Call for Abstracts: Submission deadline 3 October 2007

Why submit an abstract?

- Your achievement showcased to key international opinion leaders

- Communicate your organisation's work

- Enhance your organisation's profile

- Network with others in your area/field

- Share your success, learn from your failures

For more details and to submit your abstract online visit internationalforum.bmj.com 